\title{
ANÁLISIS DE MODALIDADES IDENTITARIAS EN UN CONTEXTO DE MIGRACIÓN
}

\section{ANALYSIS OF MODALITIES OF IDENTITY IN A CONTEXT OF MIGRATION}

María Georgina Granero

Resumen: Nos proponemos analizar modalidades identitarias en una población paraguaya asentada en el Gran Rosario (Santa Fe, Argentina). Para ello, introducimos el análisis de diferentes espacios (de inserción, sociabilidad, entre otros), en base al registro etnográfico realizado entre 2010 y 2015. Tales resultados son acompañados de una discusión sobre los aspectos teóricos y metodológicos del análisis de la identidad en contextos migratorios. Finalmente, proponemos formalizar las modalidades identificadas a fin de destacar aspectos vinculantes y contrastantes así como mecanismos operantes. Finalmente, revisaremos las posibilidades del análisis desarrollado y los correlatos socio-políticos de las modalidades identitarias identificadas.

Palabras clave: migración; identidad; antropología; Gran Rosario (Argentina).

Abstract: We propose to analyze modalities of identity in a Paraguayan migrant population settled in the Great Rosario (Santa Fe, Argentina). To do so, we introduce the analysis of different spaces (of insertion, sociability, among others), based on the ethnographic register made between 2010 and 2015. These results are presented together with a discussion about the theoretical and methodologi-

* CEAPROS, FHyA-UNR (Argentina) 
cal issues involved in the analysis of identity in migrant contexts. Finally, we propose to formalize the identified modalities to highlight similarities and contrasts as well as operative mechanisms. Finally, we review the possibilities of the analyses applied and the socio-political correlates of the modalities of identity identified.

Key words: migration; identity; anthropology; Gran Rosario (Argentina).

\section{INTRODUCCIÓN}

La migración limítrofe (mayormente, paraguaya y boliviana) hacia urbes argentinas se afianza desde mediados del siglo XX como resultado del crecimiento de estas últimas, la crisis de las economías fronterizas y particulares contextos de expulsión (Benencia, 2012; 2003; Pacecca y Courtis, 2008). Tal corriente constituye desde entonces el factor más dinámico de la composición demográfica de la población extranjera en Argentina ${ }^{1}$. En tal marco, abordamos una población de migrantes paraguayos residentes en una ciudad intermedia que, a diferencia del conurbano bonaerense, no ha sido mayormente estudiada ${ }^{2}$.

La pregunta por las modalidades identitarias de esta población parte de considerar que tales procesos identitarios, en clave nacional, definen formas históricamente situadas de "paraguayidad" en el contexto argentino (Halpern, 2009). En función de tal situacionalidad nos preguntamos cómo se realizan estas expresiones en el colectivo y contexto de referencia y, al mismo tiempo, cómo analizar la construcción identitaria en un contexto de migración en general.

El análisis de lo identitario demanda una constante revisión teórico-metodológica, particularmente exigida en contextos de migración, dada su complejidad, el potencial aporte para su estudio y para el debate social actual. En este trabajo analizamos ello desde una mirada antropológica y cualitativa que pretende sumar a otros enfoques, igualmente necesarios en el estudio de las migraciones.

1 Ello sucede al mismo tiempo que las corrientes de ultramar que constituyeron el patrón migrante por excelencia desde fines del siglo XIX hasta mediados del XX, se retraen y su población envejece.

2 El Gran Rosario (Ciudad de Rosario y localidades aledañas) es la mayor urbanización de la Provincia de Santa Fe, ubicada al sur de la misma, y tercera mayor a nivel nacional, según el último Censo de 2010. 


\section{MARCO TEÓRICO}

Por un lado, entendemos como "modalidades identitarias" una instancia de análisis que parte de reconstruir las posibles síntesis que un grupo se presta en la organización simbólica de su experiencia (Lévi-Strauss, 1981). Por otro lado, consideramos que tales expresiones presentan diferentes facetas y niveles de análisis. En concreto señalaremos que estas asumen diferentes grados de organización (o su ausencia), en la medida que indican procesos de remarcación (Halpern, 2009) plurales, esto es, con distinto eje en lo político-participativo, lo cultural y/o lo religioso. Estas expresiones y procesos convergen como punto común en la significación de la condición migrante y de la nacionalidad, las que remiten, por definición, a un orden político.

Se trata, así, de una población que asume una condición elaborada a través de trayectorias colectivas y, por tanto, en una dinámica que impide concebir dicha producción como algo establecido de antemano. A su vez, asumimos que las líneas que definen contrastes (nosotros/ellos; interno/externo) (Barth, 1976), válidos analíticamente, son móviles y relativas a pertenencias concretas (que aquí analizamos en relación a diferentes espacios). En otras palabras, no hay unilateralidad posible en este terreno: el origen nacional no anticipa una identidad ${ }^{3}$. Pero que hablemos de modalidades identitarias en plural, justamente demanda un análisis de su sentido, situado y condicionado y de su conformación.

Para ello también indicamos que estos niveles de análisis se superponen pero no necesariamente se presentan de forma homogénea y completa en la experiencia de cada migrante o en general. Complementariamente, el orden político en clave nacional que define la condición de extranjeridad y migración per se, establece el hilo conductor que nos permite vincular las diferentes expresiones desde el reconocimiento de una demanda de posicionamiento o inscripción socio-política ${ }^{4}$, exigida a las poblaciones migrantes y a

3 Aquello que Hall (2003) denomina "innecesariedad" entre correspondencias.

4 Dichos posicionamientos son socio-políticos porque la condición misma de extranjeridad y la migratoria remiten a un orden político por definición y se realizan mediante prácticas institucionales y societarias, permanentemente. Esta categorización tiene una historia asociada, relacionada a la migración limítrofe en particular en Argentina que no podemos abarcar aquí. 
la que estas responden con diferente pero nunca pleno derecho y autonomía (Sayad, 2010a).

En particular, Sayad (2010a) remarca cómo la condición de emigrante-inmigrante introduce contradicciones particulares: de una provisionalidad que dura, ausencias y presencias incompletas, hasta el vértigo de creencias y valores en transformación. En el tránsito, dicha situación admite cierto margen de redefinición:

Contradiciendo la representación que nos hacemos de él, al tiempo que se contradice del todo a sí mismo, el inmigrante actual tiende a disociarse... de la sujeción al trabajo de la que toda su existencia dependía y sigue dependiendo... se ve obligado a implicarse cada vez más, y de modo más activo, en todas las esferas de la vida nacional, a emprender una nueva relación con la sociedad de inmigración, y por tanto con su propia condición de inmigrante (y de emigrante)... (Sayad, 2010b, p. 255; el destacado pertenece a la fuente)

En otra parte, indica que, si el estatuto de inmigrante "le es enteramente impuesto desde el exterior" (2010a, p. 302), "desde el inmigrado se presenta un trabajo 'invisible', 'subterráneo', de integración como una 'segunda socialización' de hecho” (p. 311). En dicho proceso, las contradicciones iniciales se desplazan e introducen otras, vinculadas a la gradual inscripción en la sociedad habitada:

...para oponer una definición autónoma de sí, es decir, para poder definir en conformidad con sus intereses (materiales y simbólicos) los principios de definición del mundo social, esto nos lleva... a nada más que a reproducir bajo una forma invertida el estigma vinculado a la representación que se quiere combatir. (p. 358; el destacado pertenece a la fuente)

Sayad concluye que los inmigrantes "Se determinan en lucha por la determinación de las representaciones más ajustadas a los propios intereses" (p. 394).

A partir de ello y recurriendo al trabajo de Goffman, distingue entre estrategias de reconocimiento y de subversión: orientadas a reconocer los criterios valorativos (asumir el estigma) y a invertir el signo de estas valoraciones (reconocimiento positivo de los rasgos), respectivamente. Pero, si se presenta usualmente una oscilación entre ambas, Sayad insiste en que estas se realizan "sin poder ni imponer ni imponerse a sí mismo dicho reconocimiento, ni encontrar en el 
contexto de la inmigración las condiciones de posibilidad de una estrategia subversiva eficaz" (p. 359). Seguidamente, presentaremos nuestra lectura de estos elementos en el marco estudiado.

En el medio argentino, el trabajo de Halpern (2009, p. 71) sobre la construcción identitaria del colectivo paraguayo en Buenos Aires desde el concepto de "comunidad imaginaria" (Anderson, 1993), revisa la construcción históricamente situada de la "comunidad paraguaya" en Argentina. Analiza así la etnitización de la nación afirmada entre los migrantes frente al Estado paraguayo, disputando con este los sentidos que asume la "paraguayidad".

Dicho estudio nos planteó abordar el concepto "comunidad" en tanto referente clave de los procesos identitarios colectivos, al que luego sumamos el de "origen". Por un lado, acordamos que aquella alude a una pertenencia común dada por el origen nacional, la condición migratoria y el intercambio, como la posibilidad y los límites de una comunicación basada en expectativas y creencias comunes (Giobellina Brumana, 2009, p. 38). Procuramos ver en tal referente, como en el de "origen", una construcción que se actualiza en los diferentes espacios analizados y no como una entidad homogénea que los engloba ${ }^{5}$.

\section{METODOLOGÍA}

Presentamos un enfoque cualitativo basado en un registro etnográfico realizado con migrantes paraguayos asentados en el Gran Rosario entre 2010 y 2015. Tal registro consta de entrevistas grabadas (25) y observaciones con reconstrucción a posteriori (70), y alude a diferentes dimensiones del proceso migratorio: espacios de inserción (área de la construcción y el servicio doméstico ${ }^{6}$ ), mágicoreligiosos (devocionales: fiestas de la Virgen de Itatí y de Caacupép;

5 Por tal motivo, no buscamos que los entrevistados se planteen el término de "comunidad", de "origen" o de "intercambio" de forma expresa, sino que las utilizamos como herramientas de análisis.

6 Tal inserción corresponde a una marcada división por género observada en otras localidades argentinas (Bruno, 2011; 2008; Courtis y Pacceca, 2010; Del Águila y Bruno, 2010; Vargas, 2005).

7 Fiestas patronales asociadas en el contexto de origen (zonas limítrofes): una regional, Virgen de Itatí, originaria de Corrientes (Argentina) y otra nacional, Virgen de Caacupé (Paraguay). 
y terapéuticos, relativos a las prácticas de cura mágico-religiosas y de auto-atención) y de sociabilidad (mayormente encuentros informales) y relatos migratorios (trayectos y movilidades).

De dicho material sistematizamos cuatro espacios de análisis: 1. Trayectorias y relatos migratorios; 2. Espacios laborales; 3. Espacios mágico-religiosos (prácticas de cura y devocionales); 4. Espacios de sociabilidad (intercambios y expresiones vinculados al "origen": lengua, cocina regional, plantas medicinales, etc.). A partir de estos ejes y de sus resultados parciales, planteamos analizar la conformación de lo identitario a posteriori, esto es, a modo de corolario. Ello procura problematizar la condición migratoria, eje de nuestro análisis, y evitar un enfoque prescriptivo de la pertenencia (Briones, 2007, p. 61), como indicamos.

Por lo que, en primer lugar, presentamos estos resultados en función de sus correlatos identitarios; objeto del presente trabajo. Seguidamente, articulamos estos en un cuadro general desde el cual analizar la producción identitaria del colectivo migrante ${ }^{8}$. A partir de tal formalización, destacaremos aspectos vinculantes y contrastantes y mecanismos operantes. Finalmente, revisaremos las posibilidades del análisis desarrollado y los correlatos sociopolíticos de las modalidades identitarias identificadas.

\section{SÍNTESIS DE LOS RESULTADOS PARCIALES}

\subsection{Estrategias e in/visibilidad}

En principio, la conformación identitaria de la población estudiada presenta formas más visibilizadas de inscripción, relativas al espacio público e institucional, y formas menos visibilizadas, dadas en los múltiples intercambios y relaciones de la vida cotidiana y, mayormente, en espacios privados. En relación a ello, consideramos que la invisibilización es parte de una estrategia activa de posicionamiento que evita, de tal forma, una marcación incriminadora (Caggiano, 2008). Esto va de la mano de la preeminencia de instancias informales en el espacio local (espacio de sociabilidad) y de la ausencia de espacios

8 La exposición del trabajo procura reflejar el hilvanado reflexivo que realizamos y desde el cual arribamos al resultado presentado. 
organizativos o representativos (Granero, 2016a). Es en los espacios de sociabilidad donde se presenta, en primer lugar, la afirmación y remarcación de los rasgos diacríticos más identificables (Barth, 1976): lengua Guaraní, plantas medicinales y comida regional, entre otros elementos vinculantes al referente "origen". Estos conforman el diario intercambio entre vecinos, familiares y allegados.

Asimismo, muchos de estos elementos se encuentran en el ámbito mágico-religioso (prácticas de cura domésticas y mediadas por agentes de cura) y forman parte de circuitos de intercambio, en los cuales las referencias de "comunidad" y "origen" participan en su eficacia y reconocimiento (e.g. plantas medicinales traídas de Paraguay como "regalo" vs. cultivadas o adquiridas localmente). También los registramos en su expresión negativa, en la práctica de "daños" (acciones mágicas perjudiciales) como formas de exclusión, dadas a través de agentes de cura especializados o "curanderos" ${ }^{\text {". Por }}$ lo que, la efectividad referida, sino en contextos rituales, se realiza primariamente en marcos interactivos fuera de la esfera institucional. No encontramos allí estrategias de subversión y de reconocimiento "a secas". En cambio, proponemos pensar diferentes modalidades dadas tanto en el marco interactivo más próximo como respecto de referentes más amplios e identificables, como indicaremos.

Vemos además que en todos los casos se establecen diferenciaciones, sea frente a otros grupos y atributos o frente a una situación pasada y presente. Tal es el caso, de los relatos, los que analizamos en función del movimiento de retrospección-proyección por medio del cual se organiza su contenido: "allá y antes" vs. "acá y ahora"; más adelante volveremos sobre ello. En todo caso, el reconocimiento del estigma que lleva a evitar la identificación externa como "paraguayo", no implica siempre desmarcación de los rasgos asociados ${ }^{10}$. En el siguiente cuadro sistematizamos los principales rasgos y espacios identificados:

9 El espacio terapéutico contribuye a los procesos identitarios de un modo particular, dado su despliegue en el ámbito privado e informal. La "comunidad", definida aquí por la pertenencia a un sistema de creencias, se integra por vínculos de parentesco o afinidad, pero no se limita estrictamente al origen nacional o la condición migratoria.

10 Como sí ocurre entre los hijos de los migrantes entrevistados (mayormente argentinos), quienes expresamente señalan no querer ser "vistos como paraguayos" o aprender o hablar Guaraní. 
CUADRo 1

ESTRATEGIAS Y DIFERENCIACIÓN EN LA CONFORMACIÓN IDENTITARIA DE LOS MIGRANTES

\begin{tabular}{|c|c|l|l|}
\hline \multicolumn{2}{|c|}{ Estrategias } & \multicolumn{2}{c|}{ Diferenciación } \\
\hline \multicolumn{1}{|c|}{ Visibilidad } & Invisibilidad & \multicolumn{1}{c|}{ Frente a "otros": } & $\begin{array}{l}\text { Frente a situación pasada } \\
\text { (en relación a la presente): }\end{array}$ \\
\hline $\begin{array}{l}\text { Espacio público / } \\
\text { institucional }\end{array}$ & $\begin{array}{l}\text { Espacio privado / } \\
\text { informal }\end{array}$ & $\begin{array}{l}\text { 1. Sociedad mayoritaria } \\
\text { 2. Roles de género en el ámbito } \\
\text { laboral } \\
\text { 3. Grupos minoritarios - atributos } \\
\text { estigmatizados }\end{array}$ & $\begin{array}{l}\text { 4. Relatos: retrospección/ } \\
\text { proyección }\end{array}$ \\
\hline
\end{tabular}

Fuente: producción propia.

\subsection{Diferenciaciones}

1. En relación a la sociedad mayoritaria debemos considerar puntualmente las fiestas marianas registradas. Existe allí una visibilidad de rasgos diacríticos (lengua, banderas nacionales, música, etc.) cuya expresión en el espacio público es avalada desde el consenso prestado por la institucionalidad religiosa local (capilla barrial) (Granero, 2016b). De modo que dicha inscripción se realiza en un contexto ritual que permite la manipulación de tales elementos, especialmente desplegados en el marco festivo. Se trata, así, de un espacio instituyente y complementario al espacio más restrictivo del culto por el cual la "comunidad paraguaya" toma forma más definida, amparada en el marco religioso local.

En los rituales de Caacupé-í en las ciudades de Buenos Aires y Bariloche (Barelli, 2011; Halpern, 2009), la afirmación de la "paraguayidad" está vinculada a un posicionamiento cuyo atravesamiento socio-político implica una denuncia directa a la discriminación y un reconocimiento como sujeto colectivo de derechos. En el referente analizado, creemos que dicho proceso es más emergente y su impronta compite con las arraigadas estrategias de invisibilización. Por lo que, si en Caacupé-í, Halpern (2009) señala que "se desplaza el eje de lo político, desde lo clasista a lo étnico nacional" (p. 174), en nuestro caso consideramos un desplazamiento diferente, que traslada lo político-social al campo religioso. Ámbito en el cual se concibe posible y válido representarse como colectivo (Segato, 2007) y hacerlo en términos simétricos 
respecto de los locales; aunque sin evidenciar los condicionantes que los determinan: "a pesar de que somos de otro país, somos hermanos en la fe" (Olivia, 65 años; Obs. 08/09/12).

2. En el ámbito laboral planteamos la existencia de estrategias de reposicionamiento, estructuradas bajo relaciones de desigualdad (Granero, 2014). Por un lado, vemos la impronta de la lógica de acumulación capitalista y de una forma organizativa de escasa cualificación técnica y de mano de obra artesanal en el área de la construcción (Del Águila y Bruno, 2010; Vargas, 2005) o ligada al rol de género asignado a las mujeres (cuidados), en el servicio doméstico (Courtis y Pacecca, 2010; Canevaro, 2009). En ambos, se presenta una segmentación e "identificación funcional" (Vargas, 2005) que asocia origen nacional, condición migrante y nicho laboral para gestar una plusvalía y relaciones de producción específicas, ancladas en la reciprocidad y disposiciones valorativas (Del Águila, 2014; Bruno, 2008).

"Ser trabajador" como valor identificatorio, esgrimido por empleadores pero también por migrantes, implica donar la fuerza de trabajo en condiciones desiguales. A tal donación acompaña una "deuda" (marco reciprocitario), que se afianza por la mediación del contratista de origen paraguayo y de la identificación de género con las empleadoras en el servicio doméstico. Su práctica en un contexto de desigualdad hace evidente el desfasaje y, al mismo tiempo, la efectividad del encuentro entre lógicas de mercado y de reciprocidad.

En dicha configuración, los trabajadores se apropian estratégicamente de la asociación entre actividad laboral, origen nacional y género; esto, sin incidir a nivel de la estructuración desigual de las relaciones laborales. En otras palabras, se trata de "jugar con las reglas del sistema" a partir de definir prerrogativas: ampliar el marco de opciones laborales, en la construcción; volverse "indispensable" para los empleadores, en el servicio doméstico.

En ambos casos "ser recomendado" a diferentes trabajos y recomendar a otros, alimenta una cadena de donaciones y endeudamientos con diferenciales resultantes,_asimétricos y desiguales. Así, en un espacio intermedio entre lo público ("identificación funcional") y lo privado (espacios de trabajo), el margen de actuación identificado a través de tales "reposicionamientos", si bien no afecta la estructuración general, constituye una instancia central en la organización y elaboración de las trayectorias migratorias. En su faceta identitaria, 
tampoco podemos concebir dichas estrategias como plenamente de reconocimiento ni de subversión, en tanto se amparan en una identificación estereotipada y funcional para lograr un desempeño, no obstante, estratégico a nivel laboral.

En este caso, visibilidad y marcación están ajustadas a un contexto determinado en el cual tampoco se ponen en escena los condicionantes políticos y sociales quelo atraviesan. Al mismotiempo, la condición migratoria y la de género se articulan y desarticulan, por ejemplo, estableciendo identificaciones con trabajadores o empleadores locales y diferenciaciones respecto de connacionales. Entre estas últimas, para la construcción y el servicio doméstico, respectivamente, diferenciamos entre trayectorias 'colectivizadas' (grupos de trabajos) vs. 'individualizadas' (trabajadoras sin vínculos entre sí) y espacios 'concentrados' de trabajo (obras de construcción) vs. 'fragmentados' (hogares). A modo de hipótesis, creemos que ello incide en la definición del lugar de los migrantes, en sus posibilidades de organización o participación sindical, así como en el cuestionamiento de las condiciones estructurales.

Como anticipamos, analizamos esta faceta a través de formas de donación (cuidado y esfuerzo físico) que corresponden a la actuación de los migrantes. Estas equivalen a la afirmación de roles de género asociados a ciertas disposiciones ("docilidad", "reserva", "productividad"), como lugares legitimados, asignados y apropiados por los migrantes ${ }^{11}$. Estos valores identificatorios (cuasi-diacríticos) vienen a cuenta de un posicionamiento estratégico, aunque ello implique una funcionalidad favorable a la plusvalía particular de estos espacios.

3. En el plano interactivo barrial encontramos una diferenciación respecto de "otros" vinculados por el origen nacional, la condición socio-económica o la residencia ("otros internos"), pero frente a quienes se establece distancia, dada su asociación valorativa negativa. En tal línea, el apelativo "barrio de trabajadores" se alza

11 De forma complementaria, observamos formas de donación negativa que inciden en una inscripción inversa: el "descuido" en el rol femenino, cuya referencia es la maternidad, la "falta de esfuerzo" para aprender, en el caso de la construcción, y en general, la "vagancia" como antípoda del "progreso". Volveremos sobre algunas, aunque no todas, las connotaciones de estos términos, fundamentalmente ligadas a la inscripción socio-política de los migrantes y a sus disposiciones de origen. 
frente a la marcación social y mediática de este y otros barrios de las periferias urbanas argentinas como "inseguro": "Nosotros acá nos levantamos todos y tenemos un laburo [trabajo]" (Silvia, paraguaya, 27 años; Entrev. 03/08/11).

Esto se refuerza con el sentido aludido previamente en el ámbito laboral. En ambos casos, remarcarse como "trabajadores" implica distanciarse de quienes que no se "esfuerzan", no "progresan" y son calificados como "delincuentes" o "vagos". Si bien se alude mayormente a la población local (argentina), también es utilizado para desmarcarse de connacionales que no logran "progresar" y deben retornar o viven en condiciones habitacionales más precarias. En efecto, el barrio es distinguido por los migrantes por sus casas de material (mayormente construidas por ellos mismos), como expresión de un "progreso" logrado, frente a las viviendas precarias ("ranchos") que caracterizan los asentamientos irregulares o "villas". Liliana (paraguaya, 76 años) grafica esto: "Al menos tengo casita, porque vivía en la villa"; (Entrev. 13/04/11).

Sin embargo, gran parte de los migrantes residen en "villas" al arribar a Argentina. En tal caso, la distinción resulta reveladora: "[...] era villa. Pero era una villa decente. Porque todos paraguayos, entre chaqueños, todo de material las casitas, no era chapa" (Elba, paraguaya, 47 años; Entrev. 08/11/11). Significativamente, una maestra de la escuela barrial (argentina, 37 años) coincide en esta identificación: "Acá son gente humilde, pobre, pero no hay villeros [...] fijate que ellos tienen su casa, no vas a ver ranchitos de villa" (Entrev. 14/12/10).

Por último, el anecdótico "miedo" que expresa Graciela (paraguaya, 58 años), antigua residente del barrio, frente al posible asentamiento de migrantes limítrofes en terrenos lindantes a su casa (Obs. 14/12/10 $)^{12}$, instaló para nosotros una nueva fragmentación del referente colectivo. No obstante, entendemos que esto no supone sino un carácter excepcional que, como otros atributos negativos señalados, sirve para afianzar los valores identificatorios, siendo parte de estrategias de desmarcación y remarcación (Halpern, 2009).

Se trata de una otredad visibilizada y marcada como indeseada en el ámbito de la sociedad mayoritaria que, no obstante, se conjuga

12 Ello vino a cuenta de sucesos acaecidos en diciembre de 2010 en el Parque Indoamericano en Villa Soldati de la ciudad de Buenos Aires. En el marco de un conflicto por viviendas y servicios básicos, en los medios locales trascendió que los ocupantes eran de origen paraguayo y boliviano. El intento de desalojo cobró la vida de tres personas. 
con una marcación socio-espacial compartida por locales, migrantes internos y paraguayos. Desde tal punto de encuentro, forzoso, se establece otra diferenciación en el caso de "otros" paraguayos que aparecen referidos como posibles "invasores" de terrenos lindantes o como "vagos" que no logran "progresar", es decir, como parte de una desmarcación de atributos negativos y de grupos identificados con estos. Dicha desmarcación es asumida como condición necesaria (aunque no suficiente) para avalar una visibilidad muchas veces inevitable. Esto es, cuando la invisibilidad no puede ser estrategia y la visibilidad es peligrosa, esta precisa delimitarse de forma estricta.

\subsection{Fragmentación y liminaridad}

Atendiendo a los casos planteados, entendemos que estos reflejan posicionamientos no necesariamente excluyentes sino yuxtapuestos. Asociamos ello al carácter particularmente fragmentario que los procesos de elaboración identitaria presentan en los contextos migratorios. Estos procesos parten de desagregar las clasificaciones identitarias del orden nacional (extranjero-nacional) en formas particulares: tal es el caso de la identificación con vecinos y colegas chaqueños, migrantes internos, como "trabajadores" y su contraste con los locales ("menos" trabajadores).

En definitiva, es el ordenamiento político-nacional, naturalizado, el que se devela y tensiona en los procesos migratorios y en las formas de redefinición que los migrantes generan, sin disponer de los medios para imponer o imponerse un reconocimiento tal (Sayad 2010a:359). No obstante, en ciertos casos, estas pueden tomar fuerza en formas organizadas que debaten la asignación o restricción de derechos asociados y cuyo efecto amerita ser analizado.

En tal sentido, interesa destacar que la formación de rituales y representaciones (que se acercan a la esfera mítica, desde la ideológica o la política) tiende a presentarse en primera instancia "en estado de notas, de esbozos o de fragmentos” (Lévi-Strauss, 2000, p. 604) ${ }^{13}$. Tal es el caso de los relatos, centrales en la composición de las trayectorias individuales y colectivas, como desarrollaremos. En estos y en las

13 Dado que, se trate de fragmentos o de obras instituidas, los elementos a considerar son los mismos, relativos a la capacidad de simbolización, y admiten ser analizados en sus relaciones lógicas (Castaingts Teillery, 2011; Renold, 2008). 
demás elaboraciones identitarias consideramos dos tipos de efectos: efectos de institución y efectos instituyentes (Lapassade, 1977).

Situamos en el espacio de expresiones instituyentes la formulación de realidades no ajustadas a los esquemas clasificatorios nacionales, particularmente ${ }^{14}$. Estas clasificaciones trazan un límite de exclusividad entre nacionales y no nacionales a través del "doble reconocimiento" que los nacionales prestan al Estado y a sí mismos (Sayad, 2010a). Pero tal exclusión se ve trastocada en y a través de la frontera como metáfora y referente (Grimson, 2006; Bartolomé, 2005; Abinzano, 1998) y como espacio de (in)definición (Bourdieu, 2010) ${ }^{15}$.

Ello nos lleva a considerar los correlatos de la migración en la formulación identitaria también en términos de liminaridad, retomando la idea de tránsito entre estados, inicial y final de van Gennep (2008). Es decir, evaluar de tal forma los efectos de las nominaciones hegemónicas del orden nacional en la composición de la identidad (Bourdieu, 1993).

Una lectura tal se ajusta especialmente al análisis desarrollado con los relatos (punto 4 del cuadro 1). Anticipamos ya que, como historia narrada desde un presente, presentan un doble movimiento retrospectivo/proyectivo sobre la base de referencias, sino fijas en sí, necesariamente fijadas para tal elaboración (allí-aquí y antesahora $)^{16}$. En tal sentido, la instancia migratoria conforma la bisagra entre estados que tienden a definirse homogéneamente y a oponerse tanto en el espacio como en el tiempo y cuyos valores asociados son ambiguos: el destino tiende a ofrecer lo que el origen carece y viceversa (Sayad, 2010a).

Consideramos que, incluso cuando se alude a instancias desagregadas, estas presentan líneas contrastivas: sean los lugares de origen en el pasado (contexto emigratorio) y en el presente (retorno), entre una idea generalizada del "contexto de origen"

14 En un marco desigual, parafraseando a Sayad, se dirime entre ambas efectividades la "lucha" por la definición más ajustada a los intereses propios de ciertos posicionamientos (aun cuando estos no sean unívocos).

15 Somos conscientes de no abordar aquí la amplitud del debate sobre el concepto de frontera y su utilización en nuestra disciplina. En este marco, aludimos a su potencial como metáfora identitaria en función de la inscripción de las fronteras atravesadas, vividas como marcaciones.

16 Algunos enfoques cuestionan el esquema dicotómico entre instancias espaciales (aquí/allí) (Chambers, 1995). No obstante reconocer innovaciones metodológicas como la "etnografía multisituada", analizamos el desplazamiento en su referenciación (narración) a partir de hitos discontinuos en el espacio y en el tiempo. 
respecto del de "destino"; o bien, entre diferentes instancias de desplazamiento por las que se compara, por ejemplo, la experiencia de vivir en Buenos Aires y en Rosario. Por lo que, las formas de elaboración de la trayectoria migratoria, compuesta por lugares y temporalidades, tiende a ser de índole contrastiva entre: una situación anterior, preliminar, que motiva e inicia la trayectoria migratoria, y otra actualizada desde el presente, posliminar, en la que puede o no presentarse una idea de retorno.

En todo ello vemos la operación que resulta en la elaboración del “origen" como eje y referencia ineludible de los posicionamientos. Dicha relaboración se presenta desde la etapa emigratoria, en la que se gesta el desplazamiento bajo diferentes circunstancias y factores (entre los cuales, los vínculos son cruciales). Como indica Varela (2005) en su trabajo, "[...] el relato de [la] migración debe reconstruirse según esta otra secuencia: a. Condiciones en el país de origen, b. Necesidad de migrar, c. Destino atractivo, d. Viaje, e. Arribo y asentamiento" (p. 85). A ello agregamos etapas secuenciadas que desglosan este último punto y establecen un hilo conductor definido por las expectativas asociadas al lugar de destino.

Señalamos así, la centralidad de la inserción laboral, con sus mecanismos y resultantes, así como, de forma transversal, la regularización documentaria (Benza, 2000) y, paralelamente, la adquisición de propiedades y bienes materiales. En dicho tránsito, el "recurso propio", constituido a través de la recomendación laboral (síntesis de los vínculos de confianza ganados o asignados por vínculos previos), se transforma en la posesión de vivienda, aludida como objetivo central de las trayectorias. Este ideal puede ampliarse con la expectativa de "alternativas de movilidad": instancias de retorno temporales o definitivas.

De tal manera, el trabajo, la documentación, la adquisición de determinados bienes (particularmente propiedades o terrenos) y, en un segundo momento, la escolarización y profesionalización de los hijos (en aras de la inserción y la movilidad laboral), integran y configuran la representación del "progreso" y la percepción, ajustada al mismo, de los logros concebidos como posibles dentro de espacios interactivos próximos ${ }^{17}$. Tales eventos aparecen, entonces, como hitos que marcan

17 Consideramos tales disquisiciones en lo relativo al papel que juegan en la construcción del relato migratorio, sin recurrir a datos cuantitativos sobre remesas o indicadores de cambios en el nivel socioeconómico de origen y destino; lo cual sería sin duda un punto de interés. 
la trayectoria migratoria y que operan fijando puntos de referencia en un marco general de incertidumbre y, más significativamente, en la búsqueda de sentido de la propia historia frente a otros (Kyrmayer, 2003).

Sostenemos así que, a nivel de la estructuración de los relatos, la linealidad dada por el ordenamiento secuencial (Greimas, 1972) y la definición de estados contrastados (inicial/final), asume un carácter de causalidad, esto es, un efecto lógico por el cual se resuelve el sentido general de las trayectorias y de sus principales eventos. En tal línea, de una "reproducción material restringida" (a nivel laboral, socio-económico, educativo y sanitario) que motiva la emigración en el lugar de origen, se pasa a una "reproducción material ampliada" que justifica la situación migratoria actual y redefine el lugar en la sociedad de destino; siendo primariamente el anclaje material del proceso laboral. En efecto, el dinero adquirido es, en el marco capitalista (Godelier, 1998), el medio privilegiado para definir la existencia social y aquello que también permite continuar la cadena de reciprocidad y donaciones a nivel de los vínculos sociales.

En tal proceso de definición (entre otros - pero no igualmenteposibles), se concreta una forma de autonomía, aquella que permite distanciarse de los condicionamientos que forzaron la emigración y luego, incluso, del "des-enraizamiento": "Luche mucho para tener ese ranchito. Todo de mi sudor" (Zulema, paraguaya, 72 años; Entrev. 30/05/11); o como refiere Elba los terrenos adquiridos en Paraguay: "Gracias a Dios [...] tengo raíces” (Entrev. 08/11/11). Esta autonomización (aludiendo su carácter procesual) se proyecta como una resolución posible para la definición positiva de la condición migratoria, o, en palabras de Sayad, ajustada a los propios intereses.

Su límite se encuentra igualmente fijado por el anverso del "progreso", ligado íntimamente al acceso y desempeño laboral y, en ello, a la disposición valorativa como "trabajador" y sus correlatos de vulnerabilidad, como señalamos. Es allí donde vemos el carácter instituido que dicha producción identitaria tiene de cara a las clasificaciones nacionales aludidas, en la medida en que restringen el marco concreto de definición de la situación de los migrantes.

De este modo, las valoraciones que vinculan la lógica reciprocitaria (donar trabajo y lealtad) con las formas clasificatorias nacionales (paraguayos asociados a la construcción y al trabajo doméstico) en los espacios de trabajo, legitiman el lugar del migrante. Complementariamente, "la enfermedad, los accidentes que sufre el cuerpo, se representan como 'estorbos', como 'impedimentos' para 
trabajar" (Varela, 2005:124) y como verdaderos obstáculos críticos (Sayad, 2010a). Ello indica cómo la condición migratoria define sujetos que tienden a ocupar posiciones más vulnerables, a la vez que despliegan estrategias para distanciarse de tales condiciones en un horizonte de metas y expectativas (concebidas como) "posibles"18.

Así, el "progreso" (y sus correlatos materiales) forman parte de la inscripción legitimada no solo frente a la sociedad de destino, sino también de origen y frente a los no emigrados, validando su trayectoria y esfuerzo y reposicionando a los migrantes en dichos entramados, por medio de las remesas o como parte activa de la cadena migratoria. En tal sentido, planteamos que estas inscripciones acaecen a través de donaciones como sus mecanismos principales, cuyos correlatos sociopolíticos explicitan la forma no neutral que estas asumen.

Ello se complementa con disposiciones aprehendidas en el contexto de origen a partir de la historia de violencia política que tiende a desalentar la participación política (Brugnoni, 2009; Schembida, 2012) ${ }^{19}$. Señalamos que esto coadyuva a la internalización de la lógica reciprocitaria extendida a la relación Estado-ciudadanía y por la cual la extranjeridad instaura una "deuda insalvable" por los derechos otorgados y no correspondidos; representación a la que contribuyen activamente los Estados y marcos societarios intervinientes (Granero, 2016c). Entonces, en la situación primaria de ciudadanos expulsados por un Estado que no asume responsabilidad sobre ello (Palau Viladesau, 2010; Mármora, 2004; Halpern, 2001), se instauran las bases del posicionamiento analizado, por el cual las determinaciones que pesan sobre el mismo son concebidas fundamentalmente como externas y de escasa afectación por parte de los migrantes.

Complementariamente, el espacio dado a la voluntad y el esfuerzo es sintetizado significativamente en la expresión de "lucha". De tal modo, la definición de las trayectorias y los "saldos migratorios" asociados, implica también una vuelta sobre las condiciones de emigración, en tanto quien ha migrado y "progresa" sobrescribe a la fatalidad asumida, una determinación propia, aunque limitada en su autonomía.

18 En términos de Bourdieu, una illusio que compromete a los agentes a jugar dentro de determinados campos en pos de intereses ajustados a un habitus particular, traduciendo las posiciones definidas en dicho campo.

19 En ello, consideramos que la historia de violencia política, la construcción del silencio y el olvido (Arellano, 2012; 2005; Halpern, 2009; Soler, 2007), antecede la percepción de fatalidad sobre orden político, económico y social. 
Asimismo, el desajuste entre una reciprocidad extremadamente asimétrica y desigual entre Estado y persona (cuanto más, extranjera), se articula de forma implícita y eficaz con las contradicciones introducidas por el encuentro entre la universalidad de los derechos y su delimitación nacional. La naturaleza humana se encuentra, así, sino escindida de derecho, jerarquizada de hecho (Vega Solis y Gil Araujo, 2003). Los mecanismos "desajustados" de la reciprocidad ${ }^{20}$ en este contexto expresan fácticamente lo que no puede elaborar legalmente. Ello, en tanto los mecanismos convencionales anteceden y desbordan los ordenamientos más formales, generando sus propias formas reproductivas a nivel social (Pitt Rivers, 2011).

\section{FORMALIZACIÓN: MODALIDADES IDENTITARIAS Y MECANISMOS DE ELABORACIÓN}

Las estrategias de reconocimiento y de subversión corresponden a un posicionamiento respecto de la clasificación valorativa dada al origen nacional que ubica y define a los migrantes en un lugar subordinado. A partir de dicho atravesamiento, Sayad reconoce la imposibilidad de ignorarlas y, por tanto, la necesidad de apelar a su afirmación o a su negación. En nuestro caso pretendemos desagregar estas posibilidades, evidenciando procesos cuyos resultados planteamos como síntesis particulares o cierres provisorios, con diferente efecto instituyente/instituido. En tales variantes, vimos que el reconocimiento (de la posición subordinada y los atributos estigmatizados) no implica una entera desmarcación y da lugar a una remarcación que subvierte su signo negativo; ello sin (necesariamente) cuestionar las condiciones socio-políticas de su producción.

De tal modo, podemos identificar para cada uno de los espacios analizados formas de diferenciación, identificación y posicionamiento (compuestos de estrategias) que conforman las modalidades identitarias analizadas, sin con ello definir "tipos" fijos y excluyentes. Como indicamos, las modalidades identificadas se yuxtaponen y

20 "Desajustados" en tanto no son los mecanismos ni la lógica esperados o asumidos como "propios" de la relación política entre ciudadanos, extranjeros y Estado-nación. 
no pueden ser dispuestas de forma secuencial ${ }^{21}$. De tal modo, no seguimos aquí otras caracterizaciones posibles y vinculamos espacios que podrían ser diferenciados en otros aspectos ${ }^{22}$.

CuAdro $2^{23}$

\section{MODALIDADES IDENTITARIAS EN SUS ESPACIOS DE PRODUCCIÓN, MECANISMOS Y EFECTOS}

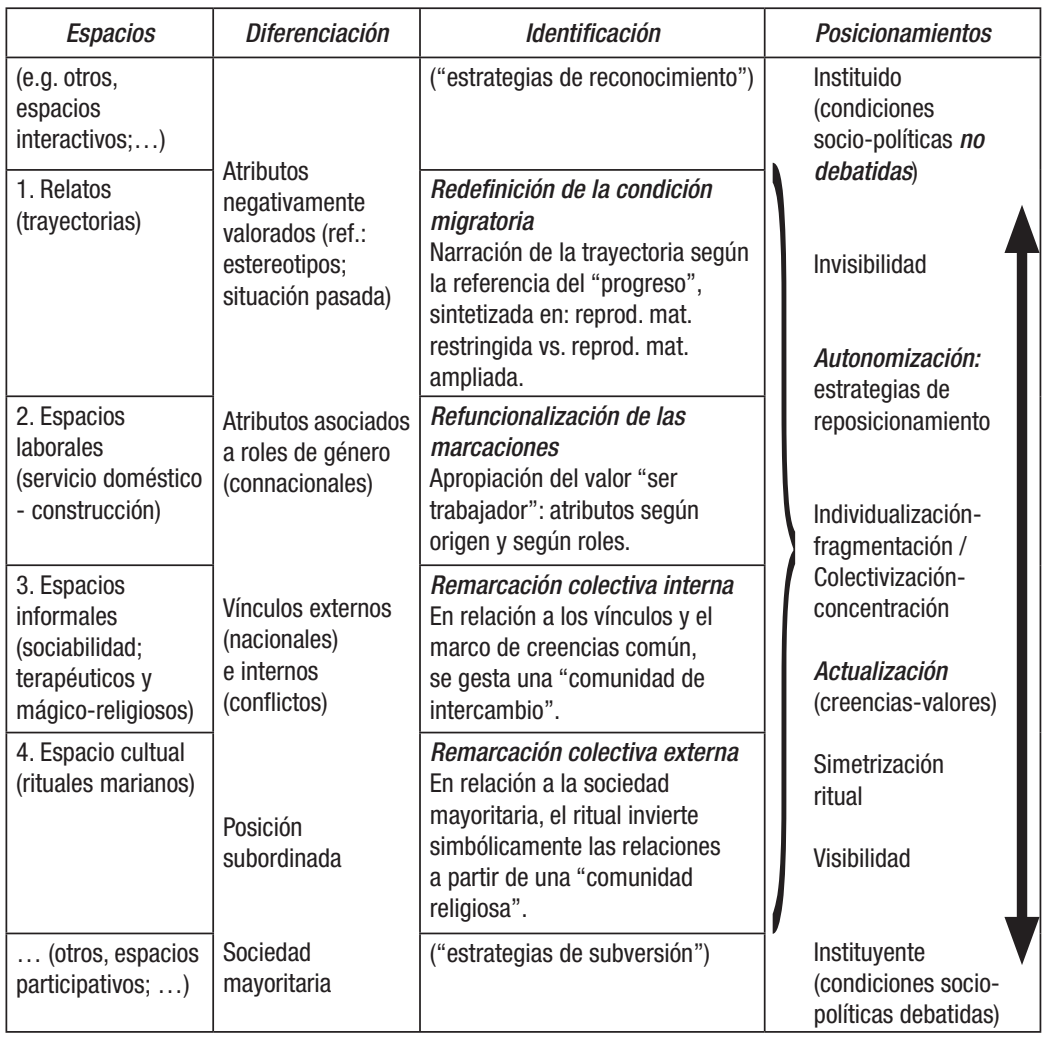

Fuente: producción propia.

21 La no coincidencia exacta de las líneas que definen los renglones pretende indicar a su vez cómo algunos rasgos atraviesan varios espacios e influyen conjuntamente en estos.

22 En efecto, reagrupamos aquí los espacios de análisis inicialmente definidos en función de los rasgos priorizados para esta lectura.

23 Agregamos estos cuadros al inicio y final con la intención de señalar espacios y formas no incluidos. 
Reordenamos las estrategias (visibilidad/invisibilidad) y las diferenciaciones, presentadas en el cuadro 1, e introducimos los componentes de "identificación" y "posicionamientos", asociándolos a cada espacio analizado. Por un lado, los posicionamientos devienen como resultado de las formas de diferenciación e identificación dadas en cada espacio (en el gráfico, indicado por la llave), a la vez que funcionan como formas estratégicas en cada espacio. Por otro, si las diferenciaciones fueron establecidas en función de los atributos y referencias asignados en cada espacio y negativamente valorados, las formas de identificación responden a dicho marco, "refuncionalizando", "redefiniendo" y "remarcando" atributos y referencias así apropiadas. En tal sentido, volvemos sobre el clásico mecanismo contrastivo que actúa en la definición de la identidad pero también pretendemos dar lugar a otro afirmativo (Briones, 2007; Grossberg, 2003). Sin que ello implique, necesariamente, una empresa crítica de los condicionantes generales que atraviesan la situación de los migrantes.

Asimismo, formando parte de los posicionamientos, indicamos los correlatos procesuales de las formas de identificación (autonomización y actualización) y las estrategias a las que se aproximan (invisibilidad/visibilidad). De modo que, en los espacios laboraleselatributovaloradode "sertrabajador" separticulariza según los atributos de género que implican y gestan respectivas estrategias de posicionamiento, formas diferenciales de autonomización y sus posibles efectos a nivel participativo (individualización vs. colectivización). Es en relación a esta cadena de atribuciones y sus correlatos a nivel socio-económico (precarización y vulnerabilidad), pero también político (sentimiento de "deuda"), que consideramos a los relatos, en su organización en torno al "progreso", generadores de efectos más instituidos que instituyentes.

Por otra parte, respecto de los espacios informales, aquí someramente tratados, ubicamos la conformación de una "comunidad de intercambio", anclada en el marco de creencias, valores y expectativas que alojan, en nuestro caso, prácticas terapéuticas y de sociabilidad, basadas en el intercambio (Giobellina Brumana, 2009). Dicha "comunidad" define sus límites hacia el exterior respecto de los "otros externos" (no creyentes nacionales) y hacia el interior, en relación a "otros internos".

De forma complementaria, la referencia a la "comunidad religiosa", centrada en la devoción mariana, pone en juego la "simetri- 
zación ritual" de los vínculos entre nacionales y migrantes, ambos devotos e "hijos" de la misma "Madre", asimismo enmarcados en la institucionalidad católica. Es allí donde ubicamos la estrategia de visibilidad, pese a tampoco implicar un abierto cuestionamiento como en otras fiestas homónimas. Es el espacio de encuentro e identificación colectiva más definido y que consideramos tiene, entonces, la posibilidad de acercarse a una redefinición más autónoma en relación a las sociedades mayoritarias (de origen y destino).

Finalmente, ubicamos una flecha de dos sentidos en el cuadro para indicar la tensión entre las estrategias y rasgos que componen los posicionamientos, tensión en el sentido del potencial de generar contradicciones y por ello cierta movilización. Esto, también en función de evitar dar una imagen estática y rígida de las modalidades presentadas.

\subsection{Mecanismos}

En base a las formas de categorización (individuación y universalización) definidas por Lévi-Strauss (2006), reconocemos los siguientes mecanismos en la formulación planteada:

1. A partir de referencias totalizadas, englobantes (origen/destino; reprod. mat. restringida / reprod. mat. ampliada; "trabajador" — migrante- / no trabajador — nacional—; interioridad/exterioridad), se establecen formas particulares a cada contexto. Así, en el plano laboral, vinculado a las diferencias de género, indicamos donaciones específicas: "cuidados" en el servicio doméstico y "esfuerzo físico" en la construcción. Entendemos este mecanismo de particularización como cumpliendo una función sintagmática, en tanto las referencias más amplias y generales se especifican a través de expresiones singulares o signos concretos.

2. Tales expresiones concretas a su vez procuran significarse en dichas referencias totalizadas, tratándose entonces de una función paradigmática en la cual las formas de inscripción restituyen su sentido a partir de categorías generales (e.g.: Cabín como "barrio de trabajadores"; las advocaciones marianas como "Madres").

Entre ambos mecanismos existe un "ida y vuelta" por el cual se consolidan tanto las expresiones concretas como las referencias generales (efecto de institución). A partir de ello, observamos como tendencia general la reafirmación de las referencias instituidas, esto 
es, en tanto no hay clara puesta en evidencia de las condiciones de producción de dichas referencias (condiciones socio-políticas no debatidas). Destacamos, no obstante, la "simetrización" ritual de las fiestas marianas: allí la inscripción de la comunidad de migrantes paraguayos apela e interpela el orden nacional y religioso instituido ante la expresión de su diferencia (política, como extranjero, sociocultural y también religiosa, en sus prácticas no institucionalizadas); aunque no lo cuestione abiertamente.

En relación a la elaboración de los relatos, a su vez, consideramos más claramente la formulación de referencias totalizantes que instauran un primer principio organizativo de la experiencia narrada: antes-ahora; allá-acá. Seguidamente, advertimos que las posibles desagregaciones de tales referencias, en alusión a desplazamientos previos, se organizan en función del mismo eje espacio-temporal contrastivo. De similar forma, las diferenciaciones respecto de "otros internos" no cuestionan sino afianzan las líneas identitarias establecidas a partir de valores representativos que asocian, por ejemplo, origen nacional y el atributo: "ser trabajador". Estas rearticulaciones implican un movimiento tautológico que tiende a reproducir el sistema de referencias y no a afianzar corrimientos que conllevarían posibles tensiones ${ }^{24}$ (efecto de institución).

Dicho de otra manera, reconocemos que el mecanismo de particularización indica la necesidad de acortar la brecha, en un esfuerzo comunicativo, entre las oposiciones mayores realizadas a nivel representacional, según la diversidad de lo vivido lo demande. Por otro, el reordenamiento posterior de las mismas, procura mantener las diferencias centrales (en un esfuerzo por incomunicarlas), en tanto estructuran lo concebido y cuya ruptura implica un costo arduo de afrontar (Lévi-Strauss, 2006) ${ }^{25}$.

Por último, consideramos que tal movimiento de segmentación y restructuración condice con la fragmentación propia del espacio liminar, al que da lugar la conformación identitaria en contextos

24 En el ámbito mágico-religioso, la afirmación del sistema de creencias también puede ser un medio de reintegrar contradicciones dispuestas en la proyección de la trayectoria ("abusos" de connacionales; enfermedad, etc.).

25 Por ejemplo, hemos analizado que en los espacios de trabajo donde el origen nacional aparece como "garantía suficiente" (Vargas, 2005), ello se altera en casos de "abuso" entre trabajadores paraguayos, o bien, frente a "inesperadas" formas de solidaridad con vínculos locales. Nuevamente indicamos que dichas excepciones no se generalizan al punto de alterar la referencia general. 
de migración y es necesaria para la generación de expresiones singulares. De allí que la introducción de ciertas desagregaciones, aunque no "desestructurantes", lleva a preguntarnos bajo qué condiciones logran consolidar desplazamientos de mayor efecto instituyente. En otros términos, si es posible tensionar el marco referencial instituido y producir referencias válidas distintas en las cuales significar la experiencia vivida. Por ejemplo, tal sería el caso de procesos de participación colectiva que no hemos registrado en el contexto estudiado por fuera del marco ritual.

\section{CONCLUSIONES}

En torno a lo identitario se instala la pregunta sobre la ficcionalidad del recorte (Althabe, 2003), que en nuestro caso podría naturalizar un sentido de 'lo nacional' sobre otros. De allí que la mirada sobre modalidades identitarias, producidas a través de los espacios observados en el entramado social, puede ser una vía promisoria para dicha empresa. En la medida en que ello no implica considerar tales trayectorias como únicas y desvinculadas entre sí, ni tampoco tomar por válida una apresurada formulación la identidad colectiva. En su lugar, situamos este análisis en la tensión, siempre presente, entre lo particular y lo general, en cuya parcial resolución se procura evidenciar la articulación de dimensiones políticas, sociales y culturales intervinientes.

Destacamos así la posibilidad de un abordaje de lo representacional, de carácter contrastivo, y su relación con los condicionamientos sociales que delinean posiciones en un marco relacional general (sociedad nacional) o específico (colectivos), como dos formas de análisis válidas y no excluyentes (Cardoso de Oliveira, 1963). Mientras que la objetivación de las referencialidades citadas (espacios) es, en todo caso, sensible al involucramiento de los sujetos de estudios en determinadas prácticas, creencias y valoraciones, como a su propia auto-adscripción, sin dejar de reconocer en ello una "síntesis problemática", producto de la investigación (LéviStrauss, 1981).

De ahí que la definición de modalidades identitarias en clave nacional, tensiona los límites de una generalización válida, pero también intenta aproximar una mirada desde su afirmación, es decir, 
no solo como efecto de contraste de una identidad previamente constituida. En función de ello, analizamos los mecanismos implicados en la conformación de las modalidades identitarias (totalización/particularización) y la preminencia que lo "instituido" (formas clasificatorias naturalizadas) tiene en estas. A partir de allí, reintroducimos la pregunta por la posibilidad de rupturas que posibiliten expresiones "instituyentes" y el debate de las condiciones de producción de las clasificaciones operantes. En otras palabras, si es posible establecer desplazamientos que "escapen" al constreñimiento tautológico que indica Bourdieu (1999) al definir la violencia simbólica como la imposición de las formas de pensar y pensarse.

De tal modo, creemos que no se trata solo de conocer los mecanismos o formas de poder y opresión para actuar (asunción por la que puede esperarse un paso directo y unificado a la acción), sino más bien de concebir posibilidades de afectación para definir eficacias alternativas. En otras palabras, la invisibilización de la génesis y los mecanismos de dominación es condición inicial y necesaria pero no suficiente para su ejercicio y mantenimiento, el cual debe instalarse como único mecanismo reproductivo eficaz. Del mismo modo, su "desvelamiento" constituye un paso ineludible pero no único ni directo, sin que este se colectivice y se materialice en prácticas y referentes posibles, aunque necesariamente limitados y no del todo autónomos.

A partir del análisis emprendido, indicaremos que tal génesis va de la mano de la reelaboración de la "comunidad" como referencia totalizada a partir de espacios de encuentro, reconocimiento y visibilidad. Si bien ello es claro en formas organizativas y participativas, la atención radica, justamente, en aquellos procesos por los que podrían formularse las referencias colectivas necesarias. Señalamos de modo especial los rituales marianos y la simbolización de la inscripción colectiva. Más allá del contenido religioso, destacamos en estos la visibilización como rasgo necesario, en tanto dicha inscripción no puede ser efectiva sino en relación a los referentes societarios (y políticos) frente a los cuales se instalan los posicionamientos adjudicados y apropiados.

En definitiva, considerando que la expresión identitaria implica la posibilidad de "mutuas afectaciones" (Grossberg, 2003), por definición, desigualmente dadas, entendemos que la ritualidad aporta en el caso registrado el instrumento y marco más directo, 
en tanto: "Los ritos representan la forma de las relaciones sociales y al darle a estas relaciones expresión visible permiten que la gente conozca su propia sociedad. Los ritos actúan sobre el cuerpo político mediante el instrumento simbólico del cuerpo físico" (Douglas, 1973:173). De modo que, si la necesaria integración de experiencias desordenadas implica generalmente la afirmación de las estructuras existentes, la posibilidad de modificación viene a cuenta de, sin negar su evidencia, establecer otros caminos que logren significar y hacer inteligible dicha experiencia, anticipar otras semejantes y poder, por tanto, aspirar a influir en ellas.

\section{BIBLIOGRAFÍA}

Abinzano, R. (1998): Globalización, regiones y fronteras. Documentos de debate $N^{o}$ 27. Francia, UNESCO. Recuperado de: http://unesdoc.unesco.org/ images/0011/001149/114958So.pdf

Althabe, G. (2003): Antropología del mundo contemporáneo e investigación de campo. Alteridades, 13(25), 7-12.

Anderson, B. (1993): Comunidades imaginadas. Reflexiones sobre el origen y la difusión del nacionalismo. México: Fondo de Cultura Económica.

Arellano, D. (2012): Proceso de Transición a la Democracia y Políticas de Reparación Social: La Comisión de Verdad y Justicia del Paraguay (Tesis magistral inédita). Facultad de Humanidades y Ciencias Sociales, Universidad Nacional de Misiones, Misiones, Argentina.

Arellano, D. (2005): Movimiento 14 de Mayo para la liberación del Paraguay. 1959. Memorias de no resignación. Misiones: EDUNAM.

Barelli, I. (2011): La Virgen de Caacupé-í símbolo de la inmigración paraguaya en San Carlos de Bariloche. IV Jornadas de Historia Social de la Patagonia. Santa Rosa, Argentina.

BARTH, F. (1976): Los grupos étnicos y sus fronteras. México: Fondo de Cultura Económica.

Bartolomé, M. (2005): Antropología de las fronteras en América Latina. AmeriQuests, 2(1). Recuperado de: http://ejournals.library.vanderbilt. edu/ameriquests/viewarticle.php?id=49

Benencia, R. (2012): Perfil migratorio de Argentina 2012. Buenos Aires: OIM.

Benencia, R. (2003): Apéndice. La migración limítrofe. En F. Devoto Historia de la inmigración en la Argentina. Buenos Aires: Ed. Sudamericana.

Bourdieu, P. (2010): Prefacio. En A. SAYAd La doble ausencia. De las ilusiones del emigrado a los padecimientos del inmigrado. Barcelona: Ed. Anthropos.

BouRdieu, P. (1999): La dominación masculina. Barcelona: Anagrama. 
Bourdieu, P. (1993): Los ritos como actos de institución. En J. PitT-Rivers y J. G. Peristiany (Eds.) Honor y Gracia. Madrid: Alianza Universidad.

BRIONES, C. (2007): Teorías performativas de la identidad y performatividad de las teorías. Tabula Rasa, 6, 55-83.

Brugnoni, P. (2009): Paraguay 2008: estruendosos cambios, silenciosas permanencias. Revista de Ciencia Política, 29, 565-590.

BRuno, S. (2011): Migrantes paraguayas y el servicio doméstico en Buenos Aires. Diferencias y desigualdades. $4^{\circ}$ Congreso Paraguayo de Población, Asociación Paraguaya de Estudios de Población, Asunción.

BRUnO, S. (2008): Inserción laboral de los migrantes paraguayos en Buenos Aires: una revisión de categorías: desde el 'nicho laboral' a 'plusvalía étnica'. V Jornadas de Investigación en Antropología Social. UBA. Buenos Aires.

Caggiano, S. (2008): Racismo, fundamentalismo cultural y restricción de la ciudadanía: formas de regulación social frente a inmigrantes en Argentina. En S. Novick (Comp.) Las migraciones en América Latina. Políticas, culturas y estrategias. Buenos Aires: Catálogos.

Canevaro, S. (2009): Empleadoras del servicio doméstico en la Ciudad de Buenos Aires: intimidad, desigualdad y afecto. Avá, 15, 187-207.

Cardoso de Oliveira, R. (1963): Aculturación y “fricción” étnica. Am. Lat., 6 (3), 33-46.

Castaingts Teillery, J. (2011): Antropología simbólica y neurociencia. Barcelona: Anthropos.

Chambers, I. (1995): Migración, cultura, identidad. Buenos Aires: Amorrortu.

Courtis, C. y PAceccA, M. I. (2010): Género y trayectoria migratoria: mujeres migrantes y trabajo doméstico en el Área Metropolitana de Buenos Aires. Papeles de Población, 16(63), 155-185.

Del Águila, A. (2014): A través de la yerba mate: etnicidad y racionalidad económica entre los trabajadores rurales paraguayos en la industria de la construcción de Buenos Aires. Antípoda, 18, 165-187.

Del Águila, A. y Bruno, S. (2010): Huellas de tierra roja en el cemento porteño. Trabajadores migrantes paraguayos de la construcción en Buenos Aires. III Taller: "Paraguay desde las ciencias sociales", Resistencia.

Douglas, M. (1973): Pureza y peligro. Buenos Aires: Siglo XXI.

Giobellina Brumana, F. (2009): Estudio preliminar. El don del ensayo. En M. Mauss Ensayo sobre el don. Forma y función del intercambio en las sociedades arcaicas. Buenos Aires: Katz.

Godelier, M. (1998): El enigma del don. Buenos Aires: Paidós.

Granero, M. G. (2016a): Migrantes paraguayos en el Gran Rosario (Argentina): acercamiento a los espacios y modos de participación. Revista Paraguay desde las Ciencias Sociales, 7, 204-229.

Granero, M. G. (2016b.): Fiestas marianas entre migrantes paraguayos e internos en el Gran Rosario (Argentina): un análisis del marco ritual. Estudios de Antropología Social - Nueva Serie, 1(1), 86-104.

Granero, M. G. (2016c): Migración paraguaya en el Gran Rosario: posicionamientos y categorías. Revista Avá, 29, 277-301. 
Granero, M. G. (2014): Trabajo e Intercambio entre migrantes paraguayos en Rosario. Revista Estudios Sociales Contemporáneos, 10, 110-122.

Greimas, A. (1972): Elementos para una teoría del relato mítico. En R. BARTHEs et al, Análisis estructural del relato. Buenos Aires: Editorial Tiempo Contemporáneo.

Grimson, A. (2006): Nuevas xenofobias, nuevas políticas étnicas en Argentina. En A. Grimson y E. Jelin Migraciones regionales hacia la Argentina. Diferencia, desigualdad y derechos. Buenos Aires: Prometeo.

Grossberg, L. (2003): Identidad y estudios culturales: ¿no hay nada más que eso? En S. Hall y P. du Gay (Comp.). Cuestiones de identidad cultural. Buenos Aires: Ed. Amorrortu.

Hall, S. (2003): ¿Quién necesita 'identidad’?. En S. Hall y P. du Gay. Cuestiones de identidad cultural. Buenos Aires: Amorrortu.

Halpern, G. (2009): Etnicidad, inmigración y politica. Representaciones y cultura política de exiliados paraguayos en Argentina. Buenos Aires: Prometeo.

HALPERn, G. (2011): Migración y ciudadanía política. Debates, victorias y derrotas". En C. Pizarro (Coord.) Migraciones internacionales contemporáneas. Estudios para el debate, Buenos Aires: Ciccus.

KIRMAYER, L. (2003): "Failures of imagination: the refugee's narrative in psychiatry". Anthropology \& Medicine, 10(2), 167-185.

Lapassade, G. (1977): Grupos, organizaciones e instituciones. Barcelona: Gedisa.

Lévi-Strauss, C. (1981): La identidad. Barcelona: Pretel.

Lévi-Strauss, C. (1995): Antropología Estructural I. Barcelona: Paidós.

Lévi-Strauss, C. (2000): Mitológicas IV. El hombre desnudo. México: Siglo XXI.

Lévi-Strauss, C. (2006): El pensamiento salvaje. México: Fondo de Cultura Económica.

Mármora, L. (2004): Las políticas de migraciones internacionales. Buenos Aires: Paidós.

Pacecca, M. I. y Courtis, C. (2008): Inmigración contemporánea en Argentina: dinámicas y políticas. Serie Población y Desarrollo $N^{o} 84$. Chile: CELADE - CEPAL.

Palau Viladesau, T. (2010): La política y su trasfondo. El poder real en Paraguay. Rev. Nueva Sociedad, 229. Recuperado de: www.nuso.org

PITT-RIVERS, J. (2011): The place of grace in anthropology. HAU: Journal of Ethnographic Theory, 1(1), 423-450.

Renold, J. M. (2008): Antropología Social. Relecturas y ensayos. Buenos Aires: Biblos.

SAYAD, A. (2010a): La doble ausencia. De las ilusiones del emigrado a los padecimientos del inmigrado. Barcelona: Anthropos.

SAYAD, A. (2010b): Elementos para una sociología de la inmigración. EMPIRIA. Revista de Metodología de Ciencias Sociales, 19, 251-257.

Segato, R. (2007): La Nación y sus Otros. Raza, etnicidad y diversidad religiosa en tiempos de Políticas de Identidad. Buenos Aires: Prometeo. 
SchembidA, R. (2012): Las bases de la inestabilidad: cultura e instituciones políticas en Paraguay. Paraguay desde las Ciencias Sociales, 1, 131-154.

SolER, L. (2007): La familia paraguaya. Transformaciones del Estado y la Nación de López a Stroessner. En A. Waldo (Dir.) La democracia en América Latina. Un barco a la deriva. Buenos Aires: Fondo de Cultura Económica. VAN GenneP, A. (2008): Los ritos de paso. Madrid: Alianza.

VARELA, G. (2005): Mujeres partidas análisis discursivo de historias de migración. Migración, globalización y género. En Argentina y Chile. Buenos Aires: Fundación Heirinch Böll.

VARGAS, P. (2005): Bolivianos, paraguayos y argentinos en la obra. Identidades étniconacionales entre los trabajadores de la construcción. Buenos Aires: Antropofagia.

Vega Solís, C. y Gil Araujo, S. (2003): Introducción. Contrageografías: circuitos alternativos para una ciudadanía global. En S. SASSEN Contrageografías de la globalización. Género y ciudadanía en los circuitos transfronterizos. Madrid: Traficantes de Sueños-Mapas. 